\title{
ANÁLISE DE EVIDÊNCIAS SOBRE A IMPORTÂNCIA DE BARREIRAS TÉCNICAS À EXPORTAÇÃO DE EMPRESAS BRASILEIRAS
}

\author{
Heloisa Lee Burnquist ${ }^{\S}$ \\ Maurício Jorge Pinto de Souza \\ Mirian Rumenos Piedade Bacchi ${ }^{\dagger}$ \\ Rosane Nunes de Faria
}

\begin{abstract}
RESUMO
Este artigo apresenta resultados de uma pesquisa aplicada a empresas brasileiras exportadoras para levantar dados primários e conduzir análises estatísticas sobre a importância relativa de barreiras técnicas ao comércio. O procedimento metodológico empregado consistiu na aplicação de testes não-paramétricos aos dados. Verificou-se que as empresas que colaboraram com a análise consideram os efeitos das barreiras técnicas sobre suas exportações relativamente mais importantes que barreiras tarifárias, outras BNTs, impostos e custo com marketing internacional. Fatores como preço, demanda externa e custo de transporte foram indicados como mais importantes que exigências técnicas. Dentre os tipos de exigências técnicas, requisitos de qualidade, aparentemente, são os que mais influenciam as exportações. Adicionalmente, verificou-se que diferentes modalidades de exigências mostraram impactos diferenciados entre os setores analisados.
\end{abstract}

Palavras-chave: barreiras técnicas, exportações brasileiras, pesquisa aplicada, testes não-paramétricos.

\begin{abstract}
This article presents results of a survey applied to Brazilian exporting firms to obtain primary data, which are subject to a statistical analysis about the relative importance attributed to technical barriers to trade. The methodological procedure used consisted in non parametric tests The firms that collaborated with the analysis indicated that technical barriers effects upon exports are relatively more important than tariff barriers, other non tariff barriers, taxes and international marketing costs. Factors such as price, external demand and transport costs seemed to be more important than technical requirements. Within the technical requirements, quality seemed to be what has most influence upon exports. In addition, different types of requirements present different impacts within the sectors evaluated.
\end{abstract}

Key words: technical barriers; Brazilian exports; applied research; non parametric tests.

JEL classification: F13.

$\S$ Professora Doutora do Departamento de Economia, Administração e Sociologia da Escola Superior de Agricultura "Luiz de Queiroz”, Universidade de São Paulo. Endereço para contato: Avenida Pádua Dias, 11. CEP: 13400.970. Piracicaba - SP. Email: hlburnqu@esalq.usp.br.

a Bacharel em Ciências Econômicas - Universidade Federal de Santa Maria UFSM. Doutorando em Economia Aplicada, DEAS/ESALQ/USP. E-mail: mjpsouza@esalq.usp.br.

$\dagger$ Professora Doutora do Departamento de Economia, Administração e Sociologia da Escola Superior de Agricultura "Luiz de Queiroz”, Universidade de São Paulo.E-mail: mrpbacch@esalq.usp.br.

\$ Bacharel em Ciências Econômicas - Universidade Federal de Viçosa. Doutoranda em Economia Aplicada, DEAS/ESALQ/USP. E-mail:rnfaria@carpa.ciagri.usp.br.

Recebido em agosto de 2006. Aprovado em junho de 2007. 


\section{INTRODUÇão}

A condução de estudos e análises empíricas quanto aos efeitos de exigências técnicas para o comércio entre países ganhou importância para a disciplina da Economia e do Comércio Internacional, particularmente após o estabelecimento de Acordos sobre Barreiras Técnicas ao Comércio e sobre Medidas Sanitárias e Fitossanitárias, entre os países membros da Organização Mundial do Comércio (OMC). Esses acordos inseriram a dimensão das exigências técnicas - que se apresentam na forma de normas, regulamentos ou procedimentos de avaliação de conformidade - no "radar comercial" dos bens e serviços entre fronteiras. As regras estabelecidas pelos referidos acordos passaram a vigorar simultaneamente à criação da OMC, a partir de 1995 (WTO Secretariat, 2006).

No entanto, a caracterização do que se constitui uma barreira técnica ao comércio ainda vem sendo um desafio, tanto para pesquisadores como para formuladores de política para o comércio internacional (Popper et al., 2004). Alguns autores atribuem essa dificuldade à existência de várias linhas de conhecimento - tais como aspectos tecnológico, legal, econômico e político - envolvidas na definição desse conceito (Henson; Wilson, 2005). Outros relacionam tal dificuldade à ausência de uma base de dados referente à existência e extensão das medidas específicas sendo disputadas (Thornsbury, 1998; Ferrantino, 2003).

De fato, ainda são poucos os países que promovem um acompanhamento sistemático destas questões no setor privado, embora iniciativas dessa natureza possam se constituir em importante referência para a padronização e divulgação de informações sobre os obstáculos técnicos às importações. Alguns desenvolvimentos nesse sentido foram conduzidos nos Estados Unidos, a princípio pelo USDA, em 1996, que realizou um levantamento e quantificação dos impactos de barreiras técnicas incidentes sobre as exportações daquele país.

Wilson e Otsuki (2004) desenvolveram uma sistemática de levantamento e divulgação de informações obtidas por meio de questionários, em nível de firmas, visando construir um banco de dados do Banco Mundial sobre normas e regulamentações técnicas. Esse levantamento foi bastante abrangente, envolvendo empresas de 17 países em desenvolvimento. No entanto, essa pesquisa não incluiu informações sobre exportadores brasileiros. Visando suprir informações primárias sobre obstáculos técnicos ao comércio internacional referentes à experiência de empresas brasileiras exportadoras, formulou-se uma pesquisa aplicada, cujos resultados são apresentados e avaliados neste artigo.

O presente artigo tem por objetivo analisar a percepção de empresas brasileiras exportadoras em relação às exigências de natureza técnica, buscando caracterizá-las e identificar sua importância relativa quando comparada a outros fatores que impedem o livre comércio. As informações foram obtidas por meio de uma amostra de 77 empresas exportadoras.

O trabalho apresenta uma discussão sobre o conceito de barreiras técnicas na Seção 2. Seguese uma breve relação de iniciativas semelhantes de levantamento de informações primárias no setor privado sobre obstáculos técnicos ao comércio internacional na Seção 3. A Seção 4 apresenta os métodos de pesquisa adotados para o questionário e análise de seus resultados. A Seção 5 apresenta os resultados, sendo que as conclusões são discutidas na Seção 6 do trabalho. 


\section{DEFINIÇÕES E REFERENCIAL TEÓRICO}

Em termos gerais, uma barreira técnica ao comércio insere-se na definição de medidas não-tarifárias (MNTs), que compreende restrições às exportações e produção, subsídios às exportações ou medidas com efeitos similares (Laird, 1997). ${ }^{1}$ A UNCTAD (1994) acumula mais de uma centena de medidas classificadas dessa forma. Segundo Laird e Vossenar (1991), citados por Laird (1997), podem ser definidas cinco categorias de medidas não-tarifárias, incluindo, além das barreiras técnicas, medidas de controle sobre o volume de importação, como quotas, medidas de controle dos preços de bens importados; medidas de monitoramento, inclusive a vigilância de preços e volumes dos importados; medidas que interferem na produção e exportação, na forma de subsídios, além de taxas ou proibições. Henson e Wilson (2005) definem como MNTs qualquer prática governamental que não seja uma tarifa, embora impeça a entrada do produto estrangeiro em um país e discrimine contra as importações.

Segerson (1999) indica que uma barreira técnica pode ser caracterizada pelo requisito técnico imposto pelo país importador, cujo atendimento aumenta os custos para as empresas exportadoras, a ponto de limitar ou mesmo impedir a continuidade do comércio. Particularmente nos casos em que as exigências no país importador são mais rigorosas que as prevalecentes no país de origem, produtores exportadores são forçados a adequar seu processo de manufatura para diferentes requisitos. Tais adequações envolvem, por exemplo, atendimento a controle de segurança e/ou qualidade dos produtos, requisitos de rotulagem e de embalagem, medidas de proteção ambiental, dentre outras (Henson; Wilson, 2005). Os custos incorridos pelas empresas nesse processo também podem resultar da necessidade de segregar os processos de produção ou redirecionar os fluxos de comércio para outros mercados, quando a adequação não é factível (Maskus; Wilson, 2001).

Quando existem diferenças nos procedimentos de certificação e teste entre os países, torna-se necessária a demonstração de conformidade para as normas. Quando as diferenças são muito acentuadas, de forma que não se consegue demonstrar a equivalência sem incorrer em custos substanciais, essas podem se tornar uma barreira ao comércio, comumente produzindo custos econômicos significativos. Além disso, esses processos geralmente são demorados, o que também pode resultar em prejuízos para o exportador (Laird, 1997).

Aparentemente não existe, no entanto, consenso na literatura econômica quanto à influência efetiva de normas técnicas para o comércio internacional; ou seja, não existe uma posição definitiva quanto a considerá-las como facilitadores ou fatores que impedem o comércio (Segerson, 1999).

De fato, o efeito líquido da imposição das barreiras não é facilmente identificável sem o respaldo de evidências empíricas. Ao contrário das tarifas, que provocam perda líquida de bem-estar econômico, particularmente para o país que as impõe, existem situações em que as barreiras técnicas podem aumentar a eficiência líquida da economia. Segundo Thornsbury (1998), isto ocorre, por exemplo, quando a exigência técnica reduz externalidades negativas associadas à oferta de produto importado que não alcance níveis de segurança e/ou qualidade, demandados pelos consumidores nacionais, podendo introduzir riscos à saúde e ambiente. No entanto, se ao impor a norma técnica, configura-se uma proteção de mercado para os produtores domésticos de bens similares aos importados, podem surgir dúvidas quanto à legitimidade da intenção governamental em utilizar esse recurso visando exclusivamente atenuar as externalidades negativas associadas.

1 Laird destaca que alguns livros-texto preferem empregar os termos "barreiras" ou "distorções"; no entanto, a referência a "medidas” é preferida pelo GATT e pela Comissão das Nações Unidas sobre Comércio e Desenvolvimento (UNCTAD). 
Uma vez introduzida, a medida regulatória tem algumas características de um bem público impuro. Os seus benefícios são considerados não rivais, porém ela é apenas parcialmente excludente (Thornsbury, 1998). Desta forma, quanto menor a externalidade negativa, tanto maior a possibilidade de a barreira técnica se tornar um instrumento de proteção comercial (líquida) e vice-versa. Quando é possível identificar a extensão pela qual o comércio é efetivamente restringido, bem como as implicações que isso traz para o bem-estar dos indivíduos, é também possível avaliar seu efeito líquido sobre o bem-estar econômico. Essa informação, por sua vez, é de importância fundamental para respaldar a resolução de contenciosos entre países, resultantes de exigências técnicas que resultam em obstáculos efetivos ao comércio internacional. No entanto, a ampla gama de medidas, juntamente com a natureza diversa das normas e de seus efeitos, tem dificultado avanços substanciais nesse sentido.

Formalmente, existe uma distinção entre "regulamentações técnicas" - como medidas mandatórias, impostas pelo governo - e as "normas", que são medidas voluntárias, geralmente impostas pelo setor privado, mas, em alguns casos, também reconhecidas por instituições governamentais. ${ }^{2}$ No debate sobre as barreiras técnicas ao comércio, o enfoque tem sido para as regulamentações técnicas e, em menor extensão, para as normas implementadas pelos governos nacionais (Henson; Wilson, 2005). No entanto, a evidência empírica vem mostrando que o comércio é cada vez mais influenciado por normas promulgadas pela iniciativa privada, seja de maneira individual ou coletivamente, que podem ou não estar confinadas às fronteiras nacionais. Neste trabalho, adota-se o termo norma como um conceito geral, incluindo todas as medidas técnicas, independente de serem ou não mandatórias, uma vez que o enfoque da análise não é afetado por tal diferenciação.

A literatura relacionada apresenta um número expressivo de modelos analíticos desenvolvidos para interpretar e quantificar os efeitos das barreiras técnicas (Roberts et al., 1999; Beghin; Bureau, 2001; Bigsby; Whyte, 2000; Henson; Loader, 2001; Maskus; Wilson, 2000; Maskus; Wilson, 2001; Maskus et al., 2004; Popper et al., 2005; Otsuki et al., 1999). No entanto, ainda não se chegou a uma conclusão quanto à sistemática mais adequada a ser adotada para avaliar os impactos econômicos das barreiras técnicas. Um possível motivo, já destacado, é que as bases de dados empíricos adequados ao teste dos modelos teóricos ainda são escassos (Thornsbury, 1998).

\section{PESQuisas RElacionadas}

Dentre as pesquisas pioneiras para a identificação das barreiras técnicas em um contexto internacional, tem-se a constituição de uma base de dados pela UNCTAD, conhecida como Trade Control Measures database of the United Nations Committee on Trade and Development [UNCTAD]. Segundo Ndayisenga e Kinsey (1994), citados por Thornsbury (1998), essa base de dados abrange todas as barreiras não-tarifárias, inclusive as técnicas. A mesma autora destaca uma pesquisa conduzida pelo Departamento de Agricultura dos Estados Unidos, o USDA, conhecida como 1996 USDA Survey of Technical Barriers to U.S. Agricultural Exports, que provê dados primários sobre medidas técnicas que causaram perdas de receitas para as empresas dos Estados Unidos em 1996. Essa pesquisa buscou identificar, por meio de uma iniciativa conjunta entre o Economic Research Service e o Foreign Agricultural Service, do USDA, obstáculos ao comércio de produtos norte-americanos que poderiam ser sujeitos a um questionamento sob o Acordo da Rodada do Uruguai.

2 Para uma discussão mais ampla dessas definições consultar Casella (1996); Fisher e Serra (1999). 
Mais recentemente, Wilson e Otsuki (2004) levantaram e organizaram informações para subsidiar análises sobre os impactos de normas e regulamentações técnicas para o comércio. Esse trabalho resultou em uma base de dados do Banco Mundial (The World Bank Technical Barriers to Trade Survey), identificado como a primeira tentativa de investigar os impactos de requisitos técnicos para as exportações dos países em desenvolvimento com base em dados primários. Em seu trabalho, atenção particular foi dada à importância dos custos de vários tipos de exigências com as quais as firmas de países em desenvolvimento se defrontam ao exportar para os mercados de países desenvolvidos. Os dados foram coletados por meio de um amplo questionário, aplicado a empresas de diversas indústrias (agrícolas, manufaturadoras e de comercialização), bem como a uma gama diversa de regiões geográficas. As informações foram coletadas em 689 empresas pertencentes a 20 indústrias em 17 países em desenvolvimento. A pesquisa possibilitou a composição de um banco de dados, disponibilizado no site do Banco Mundial (http://wwwl.worldbank.org/wbiep/st-db/Criteria. asp) que tem sido empregado em estudos aplicados (Chen et al., 2005; Maskus et al., 2004).

O trabalho de Wilson e Otsuki (2004) foi tomado como base para o desenvolvimento de uma fonte de informações visando caracterizar as barreiras técnicas para as exportações brasileiras, a partir de um levantamento de informações em empresas exportadoras, cujos resultados são reportados no presente trabalho.

\section{MÉTOdOS DA PESQUISA}

\subsection{Aplicação de questionário}

A base de dados para a pesquisa foi obtida por meio de questionário aplicado a empresas brasileiras. O questionário foi formulado a partir dos trabalhos conduzidos por Wilson e Otsuki (2004) e OCDE (2000). Algumas questões visaram caracterizar as empresas, segundo critérios identificados, relevantes para explorar resultados da natureza levantada. Para avaliar o grau de restritividade das exigências técnicas, as empresas colaboradoras foram instruídas a utilizar uma escala de Likert, que varia de 1 a 5. Nessa escala, considera-se que 1 indica nenhuma interferência e 5 indica alta interferência das exigências técnicas sobre as exportações. Para a seleção da amostra, utilizou-se como referência uma relação de empresas brasileiras exportadoras apresentadas em catálogo, disponível no site da Confederação Nacional das Indústrias - CNI, no site (www.cni.org.br). A partir dessa relação, procurou-se contatar um total de 300 empresas com exportação acima de US $\$ 1$ milhão de reais no biênio 2004/05. Optou-se pela seleção de empresas com maior valor exportado, tendo em vista a complexidade do tema e a dificuldade em obter respostas sujeitas à análise estatística, de empresas de menor valor exportado, em uma fase de pré-teste do questionário. Isto vem reforçar a importância de abordagem do tema no contexto nacional. Uma primeira fase consistiu na identificação de pessoa responsável pelas exportações com conhecimento sobre a questão de barreiras de natureza técnica. Feito o contato prévio, procedeu-se ao envio do questionário, por mensagem eletrônica, para 246 empresas, na qual se identificou a pessoa responsável. Desse total, um conjunto de 77 retornou o questionário devidamente respondido. 
Como as empresas entrevistadas pertencem a ramos de atividade econômica distintos, optouse por realizar uma agregação em grandes setores, para simplificar a apresentação dos resultados como: "Agronegócio", com base no conceito e classificação apresentada por Guilhoto et al. (2000); "Máquinas e equipamentos" e o "Automotivo", que foram definidos por abranger uma parcela importante de empresas da amostra; Químicos, Mineração, Metalúrgica e Siderurgia, denominado "Quim_Miner_Metal_Sider”, dado que poucas das empresas colaboradoras se enquadraram isoladamente em cada um desses segmentos, e "Outros", abrangendo apenas três empresas que não se enquadraram em nenhuma das categorias anteriores.

O questionário foi dividido em três grupos de questões: (i) caracterização da empresa; (ii) percepção da importância relativa das exigências técnicas e suas modalidades, e (iii) caracterização dos procedimentos de adequação e custos relacionados. $\mathrm{O}$ presente trabalho enfoca as respostas às questões dos grupos (i) e (ii), avaliando a importância relativa das exigências técnicas como obstáculos às exportações brasileiras. De maneira geral, busca-se responder às seguintes questões: Quais os segmentos e tipos de empresa mais expostos ao efeito da normalização e exigências técnicas sobre suas exportações? Qual a importância relativa das exigências técnicas quanto à interferência nas exportações?

\subsection{Procedimentos estatísticos ${ }^{3}$}

Além da análise descritiva, optou-se pela condução de testes não-paramétricos que não exigem a normalidade dos dados, tampouco a homogeneidade das variâncias dos tratamentos. $\mathrm{O}$ software utilizado foi o SPSS na versão 12.0.

\subsubsection{Kolmogorov-Smirnov}

Este teste procura verificar a adaptação dos dados provenientes de uma distribuição desconhecida $F_{0}(X)$ a uma distribuição específica $F(X)$ (no caso do presente estudo, a distribuição normal). Na hipótese nula específica, não existe diferença entre a distribuição $F(X)$ e a distribuição desconhecida $F_{0}(X)$, ou seja:

$$
\begin{aligned}
& H_{0}: F=F_{0} \\
& H_{1}: F \neq F_{0}
\end{aligned}
$$

Para a estatística do teste define-se: $F(X)=$ proporção de valores esperados $\leq \mathrm{X} ; S(X)$ $=$ proporção de valores observados $\leq \mathrm{X}$, e $F_{0}(X)=$ verdadeira função de distribuição de $\mathrm{X}$, que é desconhecida. Tem-se que $S(X)$ é uma função empírica de distribuição e é um estimador de $F(X)$. Define-se:

$$
D=\max _{x}[F(X)-S(X)]
$$

Ao nível de significância $\alpha$, rejeita-se $H_{0}$ se $D \geq \mathrm{d}$, sendo que os valores de $d$ são tabelados.

3 Esta seção foi elaborada a partir dos livros de Pestana e Gageiro (2000) e Campos (1979). 


\subsubsection{Teste de Friedman}

Este procedimento é utilizado para testar a hipótese nula na qual os tratamentos são iguais entre si, contra a hipótese alternativa em que pelo menos dois tratamentos diferem entre si. Este teste é adequado para amostras emparelhadas, visando comparar mais de duas médias; ou seja, quando existem três ou mais condições de emparelhamento. Consideram-se as seguintes hipóteses: uma hipótese nula, que considera que os tratamentos são iguais $\left(H_{o}=t_{1}=t_{2}=\ldots=t_{k}\right)$, e outra alternativa, $H_{a}$ : pelo menos dois tratamentos diferem entre si.

Mais especificamente, testa-se a hipótese de que a classificação das opções pelas empresas, implícitas nas respostas que essas apresentaram ao questionário aplicado para o presente trabalho, não é significativamente diferente entre si, contra a alternativa de que as respostas diferem no caso de pelo menos duas opções, dentro de cada resposta. O teste de Friedman equivale a um teste F aplicado aos valores atribuídos pelas $k$ amostras (observações) dentro de cada bloco, por meio do qual pode-se averiguar se as $k$ amostras são provenientes de uma mesma população ou de populações análogas, ou se provêm de populações distintas.

Segundo Campos (1979), a estatística do teste de Friedman é aproximada à distribuição do Qui-Quadrado, representada na equação (2):

$$
X_{r}^{2}=\frac{12}{n k(k+1)} \sum_{i=1}^{k} R_{i}^{2}-3 n(k+1)
$$

onde $R i$ é a soma das ordens atribuídas aos dados do tratamento $i$, nos $n$ blocos. Considerandose um ajuste para o caso de empates entre os tratamentos, calcula-se a estatística considerando a equação (3) indicada em Campos (1979):

$$
\chi^{2}=\frac{\frac{12}{n k(k+1)} \sum_{i} R_{i}^{2}-3 n(k+1)}{1-\frac{\sum_{j} T_{j}}{n k\left(k^{2}-1\right)}}
$$

com

$$
T_{j}=\sum_{i} t_{i j}^{3}-k
$$

onde $t_{i j}=$ número de observações empatadas no grupo $i$ do bloco $j$.

\subsubsection{Teste de Wilcoxon}

Caso o teste de Friedman resulte significativo, torna-se interessante identificar quais os fatores que diferem quanto ao grau de interferência nas exportações. Para tal, optou-se pelo teste de Wilcoxon, apresentado por Campos (1979), que permite verificar se a média de interferência atribuída ao fator exigências técnicas difere estatisticamente da média dada a outro fator. As hipóteses do teste são: $H_{o}: E(X)=E(Y)$ e $H_{a}: E(X) \neq E(Y)$. O cálculo do valor desse teste se baseia na diferença $D_{i}=Y_{i}-X_{i}$ e a estatística do teste, quando ocorrem empates nos resultados, é dada por: 


$$
T=\frac{W^{+}-W^{-}}{\sqrt{\sum_{i=1}^{n} R_{i}^{2}}}
$$

onde: $W^{+}$é a soma das ordens que correspondem às diferenças $D_{i}$ positivas; $W$ é a soma das ordens que correspondem a diferenças negativas; $R_{\mathrm{i}}$ é a ordem atribuída a $\left|D_{i}\right|$.

A estatística do teste quando não existem empates é dada por:

$$
T=\frac{W^{+}-\frac{n(n+1)}{4}}{\sqrt{n(n+1)(2 n+1) / 24}}
$$

Havendo empates ou para grandes amostras, a distribuição de $T$ tende à distribuição normal.

\subsubsection{Teste de Kruskall-Wallis}

A estatística de Kruskal-Wallis é utilizada para testar a hipótese de igualdade no que se refere à localização. Ou seja, a finalidade é averiguar se $k$ amostras independentes são provenientes de uma mesma população ou provêm de populações distintas (Campos, 1979). Por exemplo, o fator exigências técnicas interfere de forma diferente nas exportações dos setores da economia. As hipóteses a testar são: $H_{o}$ : as $k$ distribuições têm o mesmo parâmetro de localização; $H_{a}$ : pelo menos uma das $k$ populações têm um parâmetro de localização superior ou inferior ao das outras.

Quando o teste aplica-se a apenas 3 grupos com dimensão menor ou igual a 5, os respectivos valores podem ser obtidos de tabelas específicas, conforme apresentado em Campos (1979). Caso contrário, faz-se uma aproximação à distribuição do Qui-Quadrado com $(k-1)$ graus de liberdade. O teste é dado por:

$$
\begin{aligned}
& H=\frac{12}{n(n+1)} \times \sum_{j}^{k} \frac{R_{j}^{2}}{n_{j}}-3(n+1), \text { caso não existam empates } \\
& H_{E}=\frac{H}{1-\frac{\sum_{i}^{k}\left(t_{i}^{3}-t_{i}\right)}{n^{3}-n}} \text {, caso ocorram empates entre os resultados }
\end{aligned}
$$

onde: $n=$ dimensão da amostra; $k=$ número de grupos; $R_{j}=$ ordenações da categoria $j ; t_{i}$ $=$ número de observações empatadas de cada categoria $i$. 


\section{RESUlTAdos}

\subsection{Caracterização das empresas que participaram da pesquisa}

A Figura 1 apresenta como a amostra está distribuída entre os setores agregados. O setor do agronegócio concentra $34 \%$ das empresas da amostra, seguido dos setores de máquinas e equipamentos que representa $29 \%$ do total de empresas entrevistadas. O setor que agrega produtos exportados pela indústria química, de mineração, metalurgia e siderúrgica representou o terceiro maior porcentual das empresas colaboradoras, compondo $27 \%$ do total. Já os setores automotivos e “outros” tiveram uma participação de $4 \%$ e $6 \%$ respectivamente (Figura 1).

Figura 1 - Empresas participantes da pesquisa: participação por setores agregados

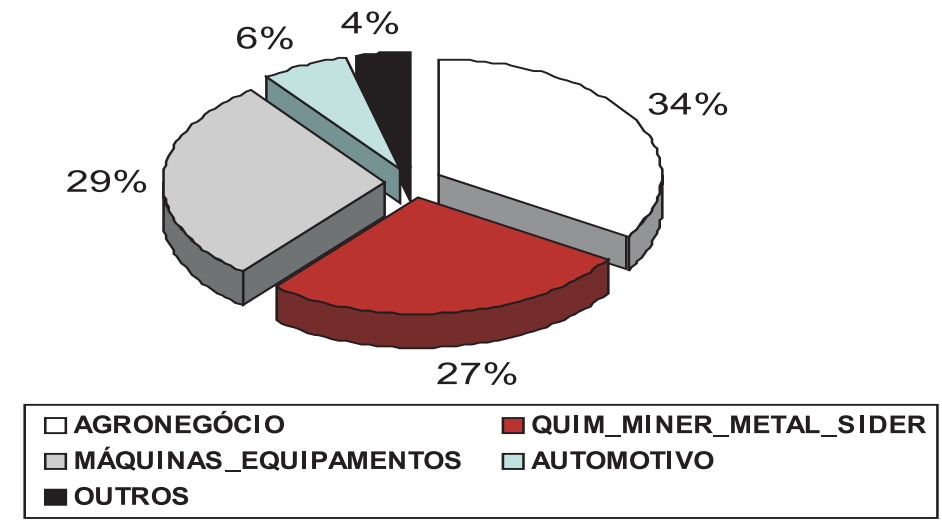

É importante analisar as empresas segundo a estrutura do capital, pois as empresas exclusivamente nacionais podem, por hipótese, ter maiores problemas com obstáculos técnicos ao comércio do que as empresas multinacionais. Um motivo é o maior ou menor acesso a informações necessárias para que possam ser tomadas medidas visando solucionar problemas com o atendimento de exigências técnicas.

Isto reforçaria, portanto, a necessidade de implantar um sistema de informações para reduzir distorções competitivas que possam estar relacionadas a obstáculos técnicos ao comércio internacional. Verificou-se que $56 \%$ das empresas participantes eram de capital nacional, sendo as restantes de capital multinacional. ${ }^{4}$ A Figura 2 caracteriza as empresas da amostra, por setores e por perfil de capital.

4 Refere-se à pergunta número 2 do questionário. 
Figura 2 - Participação das empresas que participaram da pesquisa sobre barreiras técnicas, quanto à natureza de seu capital

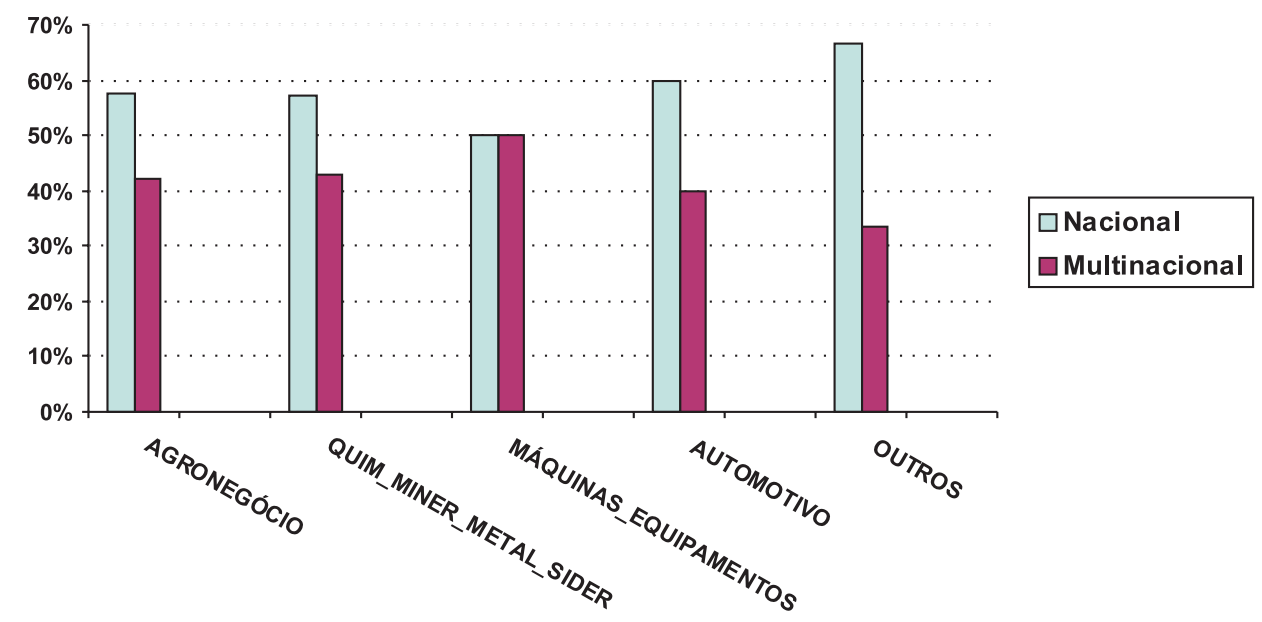

Verifica-se que $57,7 \%$ das empresas do agronegócio são de capital nacional enquanto as empresas do setor de máquinas e equipamentos estão igualmente distribuídas entre empresas de capital nacional e multinacional. Já $40 \%$ das empresas do setor automotivo são de capital nacional (Figura 2).

No que se refere aos destinos das exportações, a pesquisa revelou que 20,7\% das empresas entrevistadas têm seus dois principais mercados em países desenvolvidos, enquanto outros 39\% têm como principais destinos de seus produtos apenas países em desenvolvimento. Adicionalmente, 40,3\% das empresas entrevistadas têm seus dois principais mercados de destino diversificado entre países desenvolvidos e em desenvolvimento. A Figura 3 mostra o destino das exportações por setor para as empresas que compõem a amostra pesquisada.

Figura 3 - Destino das exportações das empresas colaboradoras por setores agregados

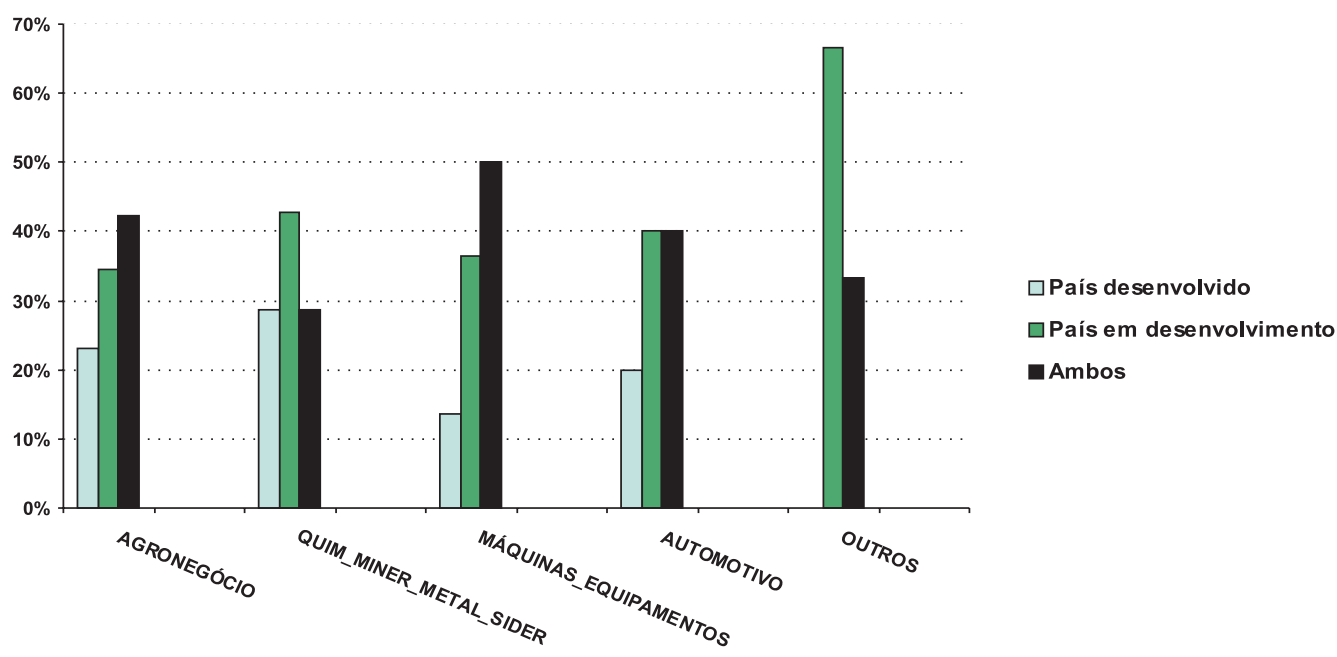


No agronegócio, $42 \%$ das empresas apresentam diversificação no destino de suas exportações, tendo entre os dois principais destinos de suas exportações um país desenvolvido e um país em desenvolvimento. No setor de máquinas e equipamentos, apenas $13 \%$ das empresas consultadas têm entre seus principais destinos mercados de países desenvolvidos.

\subsection{Resultados quanto à interferência de fatores selecionados nas exportações}

\subsubsection{Análise qualitativa}

Para comparar as exigências técnicas com outros fatores que influenciam as exportações, foram avaliadas as medidas das notas atribuídas pelas empresas ao grau de interferência em suas exportações, para oito fatores, a saber: demanda externa, preço internacional, barreiras tarifárias, exigências técnicas, barreiras não-tarifárias, impostos, custos de transporte e custo de marketing internacional. Conforme indicado anteriormente, as empresas poderiam atribuir uma nota de 1 a 5 (escala de Likert), de acordo com o grau de interferência do fator nas exportações, sendo que 1 indica nenhuma interferência e 5 alta interferência. Em termos gerais, os fatores "preço", "demanda externa" e "custo de transporte" apresentaram médias mais elevadas, indicando que são fatores identificados pelas empresas colaboradoras como os de maior impacto para as exportações.

Na última coluna da Tabela 1, tem-se a classificação da importância atribuída a cada fator de impacto sobre as exportações, independente do setor de atividade em que a empresa colaboradora se enquadra. As "exigências técnicas" aparecem como o quarto fator de maior importância indicado pelas empresas, com uma média igual a 3,08, superando "outras barreiras não-tarifárias", 5 "barreiras tarifárias”, além de "impostos” e "custo com marketing internacional” (Tabela 1).

Tabela 1 - Fatores que influenciam as exportações das empresas e a média do grau de interferência de cada fator nas exportações por setor de atividade - por setor agregado

\begin{tabular}{lrrrrrr}
\hline $\begin{array}{l}\text { Fatores de impacto } \\
\text { sobre a exportação }\end{array}$ & Agronegócio & $\begin{array}{c}\text { Quim_Miner_ } \\
\text { Metal_Sider }\end{array}$ & $\begin{array}{c}\text { Máquinas e } \\
\text { Equipamento }\end{array}$ & Automotivo & Outros & Todos \\
\hline Demanda externa & 4,04 & 3,6 & 2,91 & 3 & 2 & 3,44 \\
Preço & 3,92 & 3,95 & 3,41 & 4 & 2,67 & 3,73 \\
Custo de transporte & 3,52 & 3,6 & 3,41 & 3 & 2,33 & 3,43 \\
Exigências técnicas & 3,2 & 3,05 & 2,82 & 3,5 & 3,67 & 3,08 \\
Impostos & 3,2 & 2,5 & 2,64 & 2,5 & 2 & 2,76 \\
Barreiras não-tarifárias & 2,92 & 2,35 & 2,18 & 2,5 & 2,33 & 2,5 \\
Custo Mkt Internacional & 2,6 & 2,5 & 2,91 & 3,25 & 1,67 & 2,66 \\
Barreiras tarifárias & 2,96 & 2,65 & 2,27 & 2,25 & 1,67 & 2,58 \\
\hline
\end{tabular}

Fonte: Dados da pesquisa.

Quando o grau de interferência do fator é comparado entre os setores de atividade, o fator "exigências técnicas" assume maior importância para o setor automotivo e outros. Como esperado, para as empresas que se enquadram no setor do agronegócio, o fator "barreiras tarifárias" foi

5 O termo "outras barreiras não-tarifárias" refere-se a outras medidas não-tarifárias exceto as exigências técnicas, porém a semelhança entre estes dois conceitos pode ter levado a um viés nas respostas, de forma que a média atribuída a outras barreiras não-tarifárias pode estar superestimada. 
indicado como relativamente mais restritivo às exportações que para os outros setores, o que é um reflexo do protecionismo tarifário ainda enfrentado por este segmento da economia nacional. O fator "demanda externa” é identificado, no entanto, como o de maior grau de interferência para o agronegócio, dentre as empresas pesquisadas.

A despeito de seu valor absoluto, é interessante avaliar se as diferenças entre os valores atribuídos pelas empresas são estatisticamente significativas empregando testes adequados. Para tal, conduziu-se uma análise estatística, descrita no item a seguir.

\subsubsection{Análises estatísticas}

O primeiro procedimento de análise estatística dos dados foi o teste de normalidade nos fatores apresentados acima. Optou-se pela utilização do teste de Kolmogorov-Smirnov, cujos resultados levaram a rejeitar a hipótese de distribuição normal das variáveis (Tabela 2).

\section{Tabela 2 - Teste de Normalidade de Kolmogorov-Smirnov para os fatores que influenciam as} exportações das empresas

\begin{tabular}{|c|c|c|c|c|c|c|c|c|}
\hline Fator & $\begin{array}{c}\text { Demanda } \\
\text { externa }\end{array}$ & Preço & $\begin{array}{l}\text { Barreiras } \\
\text { tarifarias }\end{array}$ & $\begin{array}{c}\text { Exigências } \\
\text { técnicas }\end{array}$ & $\begin{array}{l}\text { Barreiras } \\
\text { não- } \\
\text { tarifarias }\end{array}$ & Impostos & $\begin{array}{c}\text { Custo } \\
\text { transporte }\end{array}$ & $\begin{array}{c}\text { Custo_Mk } \\
\text { Internacional }\end{array}$ \\
\hline Kolmogorov-Smirnov Z & $1.921^{*}$ & $1.921^{*}$ & $1.772^{*}$ & $1.563^{*}$ & $1.855^{*}$ & $1.629^{*}$ & $1.858^{*}$ & $1.988^{*}$ \\
\hline
\end{tabular}

Nota: * significativo a $1 \%$.

Desta forma, procedeu-se aos testes não-paramétricos de Friedman ( $\chi^{2}$ de Friedman) e Wilcoxon, visando verificar se existe diferença estatisticamente significativa entre os efeitos dos diferentes fatores sobre as exportações das empresas.

O valor calculado do teste de Friedman $\left(\chi_{\mathrm{c}}^{2}=96,95\right)$ implica rejeitar a hipótese nula de que não existe diferença entre a influência dos fatores sobre as exportações das empresas, ao nível de significância de $1 \%$.

Os resultados do teste de Wilcoxon, aplicado para comparar pares de fatores, revelam que a média de interferência atribuída ao fator exigências técnicas $\left(t_{1}\right)$ difere, ao nível de significância de $5 \%$, da média atribuída a cada um dos outros fatores $\left(t_{2,}, \ldots, t_{8}\right)$ - Tabela 3. Este teste permite ainda concluir que fatores como a "demanda externa", "preço" e "custo de transporte" têm maior grau de interferência nas exportações das empresas do que as exigências técnicas. De forma semelhante, as "exigências técnicas" apresentam maior influência nas exportações das empresas quando comparadas a fatores como: "barreiras tarifárias”, “outras barreiras não-tarifárias”, "impostos” e "custo de marketing internacional”.

Estes resultados sugerem, ainda, que o problema com exigências técnicas é sentido por todas as empresas consultadas, independentemente do setor a que pertencem, da estrutura de seu capital, bem como do mercado de destino de suas exportações. 
Tabela 3 - Teste de Wilcoxon para a diferença entre os fatores listados abaixo e o fator exigências técnicas

\begin{tabular}{|c|c|c|c|c|c|c|c|}
\hline Fator & $\begin{array}{c}\text { Demanda } \\
\text { externa }\end{array}$ & Preço & $\begin{array}{l}\text { Barreiras } \\
\text { tarifarias }\end{array}$ & $\begin{array}{c}\text { Barreiras } \\
\text { Não-tarifarias }\end{array}$ & Impostos & $\begin{array}{c}\text { Custo } \\
\text { Transporte }\end{array}$ & $\begin{array}{c}\text { Custo_Mk } \\
\text { Internacional }\end{array}$ \\
\hline Valor do teste & $-2.411^{* *}$ & $-3.874^{*}$ & $-3.261^{*}$ & $-3.313^{*}$ & $-2.126^{* *}$ & $-2.000^{* *}$ & $-2.427^{* *}$ \\
\hline
\end{tabular}

Notas: ${ }^{*}$ significativo a $1 \% ;{ }^{* *}$ significativo a $5 \%$.

Para verificar se a influência do fator exigências técnicas nas exportações apresenta diferença estatisticamente significativa entre setores, utilizou-se o teste não-paramétrico de Kruskal-Wallis. Os resultados deste teste não permitem concluir, no entanto, que a influência das exigências técnicas sobre as exportações diferencia-se entre os setores (Tabela 4). De forma similar, quando o mesmo teste é realizado para verificar se as exigências técnicas interferem de maneira diferente quando a empresa é de capital nacional ou multinacional, não foi identificada uma diferença com significância estatística (Tabela 4). Este mesmo resultado é obtido quando se comparam os efeitos das exigências técnicas entre empresas que têm como mercado de destino apenas países desenvolvidos, apenas países em desenvolvimento, ou ainda, que exportam para ambos os mercados (Tabela 4).

Tabela 4 - Teste de Kruskal-Wallis para influência do fator exigências técnicas nas diferentes agregações das empresas amostradas

\begin{tabular}{lrrcc}
\hline Fator & Setores & $\begin{array}{c}\text { Capital (nacional vs } \\
\text { multinacional) }\end{array}$ & $\begin{array}{c}\text { Destino (países desenvolvidos, países } \\
\text { em desenvolvimento, ambos) }\end{array}$ \\
\hline \multirow{3}{*}{ Exigências técnicas } & $\mathrm{c}^{2}$ & 2.989 & 0.013 & 0.023 \\
& $\mathrm{GL}$ & 4 & 1 & 2 \\
& Sig. & 0.560 & 0.910 & 0.988 \\
\hline
\end{tabular}

\subsection{Resultados quanto à interferência atribuída pelas empresas aos diferentes tipos de exigências técnicas}

\subsubsection{Análise qualitativa}

A Tabela 5 apresenta a média do grau de interferência dentre diferentes tipos de exigências técnicas, registrado pelas empresas exportadoras brasileiras de cada setor agregado. As exigências referentes à qualidade das exportações aparecem com maior média de interferência nas exportações, quando se consideram as respostas por setor agregado, separadamente, exceto para as categorias agregadas em outros (Tabela 5). 
Tabela 5 - Média do grau de interferência nas exportações dos diferentes tipos de exigências técnicas por setor agregado

\begin{tabular}{lrrrrrr}
\hline & \multicolumn{5}{c}{ Setor agregado } \\
\cline { 2 - 7 } Tipo de exigência & Agronegócio & $\begin{array}{c}\text { Quim_Miner_ } \\
\text { Metal_Sider }\end{array}$ & $\begin{array}{c}\text { Máquinas e } \\
\text { Equipamento }\end{array}$ & Automotivo & Outros & Todos \\
\hline Padrões & 3,69 & 3,3 & 2,55 & 3,2 & 3,33 & 3,21 \\
Característica & 3,5 & 3,5 & 2,59 & 3 & 2,33 & 3,16 \\
Embalagem & 3 & 2,6 & 2,55 & 2,2 & 3 & 2,71 \\
Rotulagem & 2,35 & 2,15 & 1,95 & 1 & 2,33 & 2,09 \\
Testes & 3,42 & 3,6 & 2,82 & 2,8 & 4 & 3,28 \\
Qualidade & 3,92 & 3,86 & 3,05 & 3,4 & 4 & 3,62 \\
Segurança & 3,12 & 3,19 & 3,23 & 1,6 & 4 & 3,1 \\
Ambiental & 3,19 & 3,15 & 2,64 & 2,2 & 3,67 & 2,97 \\
\hline
\end{tabular}

Os fatores seguintes, por ordem de importância, são as exigências de testes e de padrões, respectivamente. Âs exigências de rotulagem, por sua vez, foram atribuídos os menores graus de interferência, quando comparados aos graus dos demais tipos de exigências técnicas.

Em termos setoriais, exigências de padrões mostraram maior grau de interferência no setor Agronegócio, enquanto exigências de características apresentam maior importância para o setor de Máquinas e Equipamentos. Exigências ambientais e de qualidade têm maior grau de importância também para o Agronegócio.

\subsubsection{Análises estatísticas}

O teste de Kolmogorov-Smirnov revelou que os diferentes tipos de exigências técnicas não apresentam distribuição normal, de forma que a análise estatística dos resultados deve ser feita por meio de testes não-paramétricos (Tabela 6).

O teste de Friedman $\left(\chi_{\mathrm{c}}^{2}=123,38\right)$ aponta, ao nível de significância de $1 \%$, em favor da hipótese de que pelo menos um dos tipos de exigências técnicas afeta de maneira diferente as exportações das empresas amostradas.

Tabela 6 - Teste de Normalidade de Kolmogorov-Smirnov para os diferentes tipos de exigências técnicas que influenciam as exportações das empresas

\begin{tabular}{|c|c|c|c|c|c|c|c|c|}
\hline Tipo de exigência & Padrão & Característica & Embalagem & Rotulagem & Teste & Qualidade & Segurança & Ambiental \\
\hline Kolmogorov-Smirnov Z & $1.69^{*}$ & $1.87^{*}$ & $1.67^{*}$ & $1.91^{*}$ & $1.62^{*}$ & $2.36^{*}$ & $1.69^{*}$ & $1.34^{* *}$ \\
\hline
\end{tabular}

Notas: ${ }^{*}$ significativo a $1 \% ;{ }^{* *}$ significativo a $5 \%$.

Dada a importância das exigências de qualidade e de padrões, optou-se por comparar todos os outros tipos de exigências técnicas com estes primeiros, utilizando o teste de Wilcoxon, adequado para análise de pares de variáveis. Os resultados confirmam que exigências de qualidade do produto interferem, em média, de maneira mais significativa que exigências de padrões. Adicionalmente, exigências de qualidade apresentam, em média, uma influência nas exportações das empresas 
estatisticamente maior que os demais tipos de exigências técnicas, conforme constatado na análise qualitativa (Tabela 7). As exigências referentes a padrões, por sua vez, foram identificadas com maior grau de interferência nas exportações quando comparadas a exigências de rotulagem e de embalagem (Tabela 7).

Tabela 7 - Teste de Wilcoxon para verificar a diferença estatística entre os tipos de exigências técnicas ${ }^{6}$

\begin{tabular}{lcccccccc}
\hline Exigência & Padrões & Característica & Embalagem & Rotulagem & Testes & Qualidade & Segurança & Ambiental \\
\hline Exigência padrões & - & -0.407 & $-3.222^{*}$ & $-6.015^{*}$ & -0.350 & $-3.849^{*}$ & -0.576 & -1.441 \\
Exigência qualidade & $-3.849^{*}$ & $-3.992^{*}$ & $-5.572^{*}$ & $-6.831^{*}$ & $-3.215^{*}$ & - & $-3.372^{*}$ & $-4.651^{*}$ \\
\hline
\end{tabular}

Nota: " significativo a $1 \%$.

Para verificar se a influência nas exportações de cada um dos tipos de exigências apresenta diferença estatisticamente significativa entre setores, utilizou-se o teste não-paramétrico de Kruskal-Wallis. Ao nível de significância de $10 \%$, o teste permite rejeitar a hipótese de que as exigências de padrões, de característica, de rotulagem, de qualidade e exigências de segurança afetam de maneira igual os diferentes setores (Tabela 8). Assim, pode-se afirmar que esses diferentes tipos de exigências técnicas têm impacto diferenciado entre os setores da economia.

Tabela 8 - Teste de Kruskal-Wallis para influência dos tipos de exigências técnicas nas diferentes agregações das empresas amostradas

\begin{tabular}{lcccccccc}
\hline Exigência & Padrões & Característica & Embalagem & Rotulagem & Testes & Qualidade & Segurança & Ambiental \\
\hline Setores & $9.294^{* *}$ & $8.408^{* * *}$ & 3.958 & $8.873^{* * *}$ & 5.630 & $9.324^{* *}$ & $9.659^{* *}$ & 6.142 \\
Capital & 1.615 & 0.987 & 2.142 & 1.234 & 0.796 & 1.261 & 0.036 & 0.042 \\
Destino & 3.800 & 0.137 & 0.114 & 0.110 & 3.207 & 1.464 & 1.735 & 0.502 \\
\hline
\end{tabular}

Notas: ${ }^{*}$ significativo a $5 \% ; * *$ significativo a $10 \%$.

\section{CONCLUSÕES}

De maneira geral, pode-se deduzir que o procedimento aplicado para a condução da análise aplicada foi adequado para avaliar a sensibilidade relativa das empresas exportadoras nacionais às questões de barreiras técnicas ao comércio internacional. Embora questões complementares possam ser definidas para levantar e analisar a percepção das empresas quanto ao impacto relativo das restrições de natureza técnica, a pesquisa conduzida mostrou-se adequada para a avaliação a que se propôs.

Um aspecto importante captado pela análise é que praticamente todas as empresas consultadas identificaram as exigências técnicas como um fator que tem efeito sobre as suas exportações. Além disso, as empresas apresentaram um posicionamento que permite concluir que os efeitos

6 Como mencionado anteriormente, o teste de Wilcoxon é conduzido comparando as variáveis duas a duas. Portanto, por exemplo, é verificada a diferença entre exigências de característica e exigências de padrões, posteriormente é realizada a comparação entre a exigência de característica e a exigência de qualidade. 
das exigências técnicas são percebidos pelas empresas de forma diferenciada dos efeitos de outros fatores que afetam suas exportações. Um resultado particularmente relevante para a formulação de política comercial é que, atualmente, as exigências técnicas são percebidas pelas empresas como um fator de restritividade mais alta que as barreiras tarifárias.

Estes aspectos foram confirmados pela significância estatística de testes não-paramétricos aplicados aos resultados dos questionários ministrados às empresas exportadoras brasileiras. Tais resultados sugerem, ainda, que o problema com as exigências técnicas é sentido por todas as empresas consultadas, independente do setor a que pertencem, da estrutura de seu capital (nacional ou multinacional), bem como do destino de suas exportações (para países desenvolvidos, em desenvolvimento ou ambos).

Quando se procura avaliar, no entanto, se a percepção das empresas varia entre os setores agregados quanto à importância que esses atribuem especificamente ao fator exigência técnica, os testes estatísticos sugerem que não haveria essa diferença. Estes resultados não corroboram, portanto, as hipóteses de que as empresas nacionais captam esses efeitos de forma diferenciada relativamente às empresas multinacionais. Tampouco foi possível confirmar se os efeitos são, de fato, diferenciados segundo o mercado de destino, quando esses são separados em países desenvolvidos, países em desenvolvimento ou ambos. Esses aspectos são importantes para a definição de estratégias comerciais, merecendo, portanto, análise mais detalhada. É possível que uma extensão no número de empresas amostradas também seja útil para que sejam feitas afirmações mais incisivas a esse respeito. Deve-se considerar, ainda, que, dentre as 77 empresas que responderam à pesquisa, uma porção expressiva (34\%) inseriu-se no agronegócio, o que pode introduzir alguma tendenciosidade nas respostas obtidas. A análise do capital das empresas indica que essas incluíram de uma maneira relativamente eqüitativa, tanto aquelas com capital nacional, como a de capital multinacional. No que tange ao destino dos bens exportados para essas mesmas empresas, verifica-se uma participação relativamente equilibrada entre países desenvolvidos e em desenvolvimento, embora prevaleça o destino misto.

As evidências captadas pelo estudo levam a concluir que a inclusão das barreiras técnicas no "radar comercial" já é uma realidade para as exportadoras brasileiras. Pode-se considerar, portanto, que iniciativas que representem maior investimento na captação e sistematização de informações relacionadas a esses obstáculos são procedentes, devendo ser estimuladas.

\section{RFERÊNCIAS BIBLIOGRÁFICAS}

Beghin, J. C.; Bureau, J. C. Quantification of sanitary, phytosanitary, and technical barriers to trade. Ames, Iowa, USA: Center for Agricultural and Rural Development Iowa State University, 2001. (Trade Policy Analysis Working Paper 01-WP 291).

Bigsby, H.R.; Whyte, C. F. Quantifying phytosanitary barriers to trade. In: Hooker, N.; Murano, E. (Ed.). Interdisciplinary Food Safety Research. CRC Press. USA, 2000.

Campos, H. de. Estatística experimental não-paramétrica. 3a.ed.. Piracicaba, São Paulo, Brasil, 1979.

Casella, A.. Free trade and evolving standards. In: Bhagwati, Jagdish; Hudec, Robert E. (Ed.) Fair trade and harmonization prerequisites for free trade? Cambridge, MA e London: MIT Press, 996. p. 119-156 (v. Economic Analysis, Cap. 3)

Chen, M. X.; Otsuki, T.; Wilson, J. S. Do standards matter for export success? 2006. (World Bank Policy Research Working Paper 380). 
Confederação Nacional das Indústrias. Catálogo de exportadores brasileiros. Disponível em :<http://www. cni.org.br >. Acesso em: jun. 2006

Ferrantino, M. J. Analytical approaches to quantifying economic effects of non-tariff measures. In: WTO: Competing Policy Issues and Agendas for Agricultural Trade. Farm Foundation and the Economic Research Service of the U.S. Department of Agriculture, September 17, 2003, Washington, D.C. (U.S. International Trade Commission Office of Economics 500 e St. SW Washington, D.C. 20436).

Guilhoto, J. J. M.; Furtuoso, M. C. O.; Barros, G. S. C. O Agronegócio na economia brasileira: 1994 a 1999. Centro de Estudos Avançados em Economia Aplicada - ESALQ/USP. Piracicaba, 2000. Disponível em: < http://www.cepea.esalq.usp.br/pib/other/relatorio_metodologico.pdf>. Acesso em: 20 jul. 2006.

Henson, S.; Loader, R.. An assessment of the costs for international trade in meeting regulatory requirements. 2001. (Unclassified TD/TC/WP (2002)38/Final Working Party of the Trade Committee).

Henson, S.; Wilson, J. S. A review of key issues. In: Henson, Spencer; Wilson, John S. (Ed.) The WTO and technical barriers to trade. Cheltenham, UK. Northhampton, MA, USA, 2005. 527p. (An Elgar Reference Collection).

Laird; S. Quantifying commercial policies. In: Francois, J. F.; Reinert, K. A. Applied methods for trade policy analysis. A handbook. USA: Cambridge University Press, 1997.

Maskus; K.E.; Wilson, J. S.; Otsuki, T. Quantifying the impact of technical barriers to trade: a framework for analysis. Washington D.C: World Bank, 2000. (World Bank Policy Research Working Paper n. 2512).

Maskus, K.E.; Wilson, J. S. Quantifying the impact of technical barriers to trade: can it be done? In: Henson, Spencer; Wilson, John S. (Ed.) The WTO and technical barriers to trade. Cheltenham, UK. Northhampton, MA, USA, 2005. 527p. (An Elgar Reference Collection).

Maskus; K. E.; Otsuki, T.; Wilson, J. S. The costs of complying with foreign product standards for firms in developing countries: an econometric study institute of behavioral science research program on political and economic change. University of Colorado at Boulder, 2004. (Boulder CO 80309-0484 Working Paper PEC2004-0004).

OCDE. An assessment of the costs for international trade in meeting regulatory requirements. 2000, 102p. (Working Party of the Trade Committee).

Pestana, M. H.;, Gageiro, J. N. Análise de dados para ciências sociais - A complementaridade do SPSS. 2. ed.. Lisboa, 2000.

Popper, S. W.; Greenfield, V.; Crane, K.; Malik, R. Measuring economic effects of technical barriers to trade on U.S. exporters. USA - NIST - U.S. Department of Commerce Technology Administration, 2004

Roberts, D.; Josling, T. E.; Orden, D. A framework for analyzing technical barriers in agricultural markets. 1999. (Market and Trade Economics Division, Economic Research Service, U.S. Department of Agriculture. Technical Bulletin n. 1876).

Segerson, K. Mandatory versus voluntary approaches to food safety. Agribusiness, v.15, n.1, p. 53-70, 1999.

Thornsbury, S. Technical regulations as barriers to agricultural trade. Dissertation (Doctor of Philosophy in Agricultural and Applied Economics) - Faculty of Virginia Polytechnic Institute and State University, Blacksburg, Virginia, USA, 1998.

Wilson, John S.; Otsuki, T. Standards and technical regulations and firms in developing countries: new evidence from a world bank technical barriers to trade survey. Washington, USA: The World Bank, 2004. (Preliminary Draft).

WTO Secretariat. Handbook on the technical barriers to trade agreement. Geneva, 2006. 


\section{ANEXO \\ PESQUiSA APLICADA: PANORAMA DE EXIGÊNCIAS TÉCNICAS ÀS EXPORTAÇÕES BRASILEIRAS}

\section{INFORMAÇÕES GERAIS DA EMPRESA}

Nome da empresa

Ramo da empresa

Pessoa contatada

Cargo

E-mail

Telefone para contato

1. Indique a alternativa que melhor caracteriza a sua empresa:
$\square$ Nacional
$\square$ Multinacional

2. Indique em qual faixa de valor total de exportação anual sua empresa se enquadra:
$\square$ menos que US\$1 milhão
$\square$ US $\$ 1$ a 10 milhões $\square$ entre US $\$ 10$ e 50 milhões
$\square$ acima de US\$50 milhões

3. Indique os dois principais países (ou blocos econômicos) de destino das exportações de sua empresa:

\section{País de Destino}

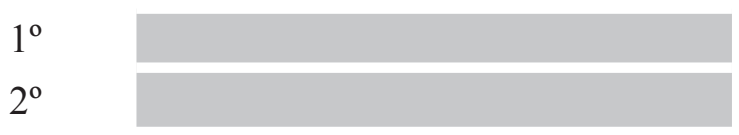

4. Classifique os fatores de acordo com o grau de interferência nas suas exportações.

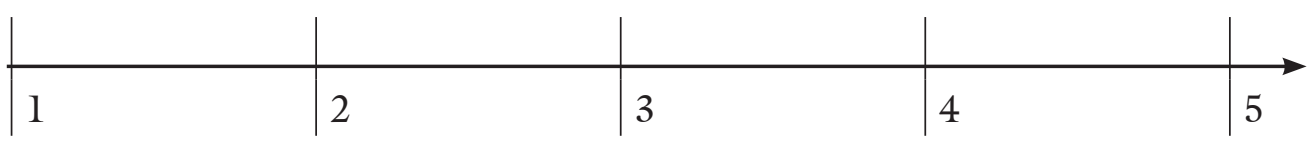

$\begin{array}{llll}\text { Nenhuma } & \text { Baixa } & \text { Média } & \text { Muito Alta }\end{array}$

Demanda externa

Preço internacional

Barreiras tarifárias

Exigências técnicas
Outras Barreiras Não-Tarifárias

Impostos

Custo de transporte

Custo de marketing internacional

Para responder às questões a seguir, tenha em mente que exigências técnicas em algum momento precisaram ser atendidas, mesmo que atualmente elas não se configurem como impedimentos às exportações. 
5. Classifique os regulamentos e normas técnicas de acordo com o grau de interferência nas suas exportações.

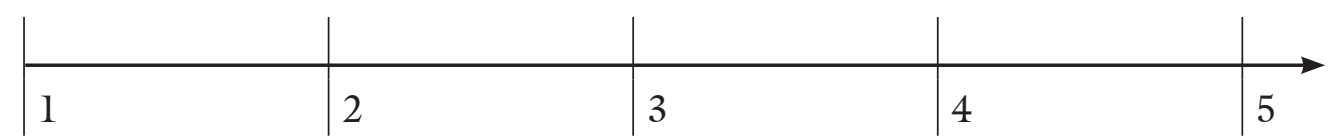
Nenhuma
Baixa
Média
Alta
Muito Alta

\section{Regulamentos técnicos impostos pelos governos}

Normas e exigências técnicas feitas pelos compradores privados

6. Classifique as exigências técnicas de acordo com o grau que elas interferem nas suas exportações:

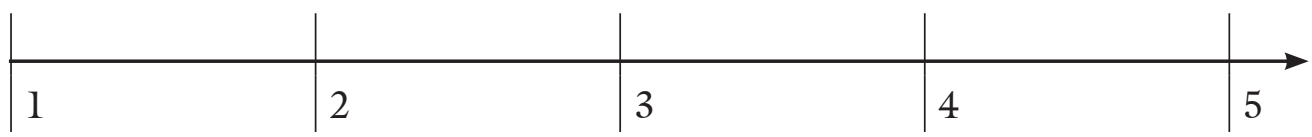
Nenhuma
Baixa
Média
Alta
Muito Alta

Padrões no processo de produção

Características do produto (tamanho, cor, peso)

Embalagem (dimensão, material utilizado)

Rotulagem (composição nutricional, validade)

Testes de avaliação de conformidade

Especificações de qualidade

Requerimentos de segurança

Exigências ambientais

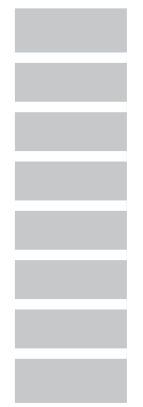

7. Durante os dois últimos anos, a sua empresa necessitou se adequar a alguma exigência técnica?

$\square \operatorname{Sim}$ $\square$ Não

Em caso positivo:

- Qual foi o porcentual de aumento no custo total de exportação:

$\square$ Menos de $1 \%$
$\square 1-4 \%$
口 5-9\%
口 $10-15 \%$
口 $16-25 \%$

- Mais de 25\% 
8. Seus produtos são certificados - para assegurar que atendem às exigências técnicas - antes de começar a exportar?
$\square \operatorname{Sim}$
$\square$ Não

Em caso positivo:

- Quem requisita os testes? (Indique as alternativas que se aplicam a sua empresa)
$\square$ O governo
$\square$ Os compradores

- Quem realiza os testes? (Indique as alternativas que se aplicam a sua empresa)

$\square$ A própria empresa

$\square$ Agência oficial do país importador

$\square$ Agência reconhecida pelo país importador

9. Marque se sua empresa adota ou pretende adotar alguns dos padrões internacionais listados abaixo. Para aqueles que você assinalar, classifique de acordo com o grau que eles interferem em suas exportações.

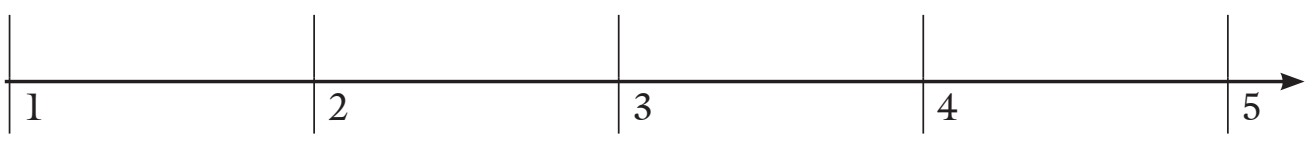
Nenhuma
Baixa
Média
Alta
Muito Alta

\section{Interferência}

$\square$ International Standards Organization (ISO)

$\square$ CODEX Alimentarius Commission

$\square$ International Plant Protection Convention (IPPC)

$\square$ Office International of Epizootics (OIE)

$\square$ Outros padrões exigidos pelos seus principais compradores (especificar)

$\square$ Outros (especificar)

$\square$ Não adoto

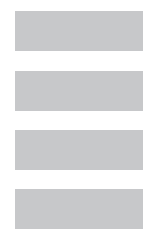

\section{Outros padrós exigidos pelos seus principais compradores (especificar)}

\section{Não adoto}

10. Existe algum custo de adequação para a sua empresa no momento da adoção dos padrões internacionais?
$\square \operatorname{Sim}$
$\square$ Não

Em caso positivo:

- Indique a percentagem de aumento no custo.
$\square 1-4 \%$
- $5-9 \%$
- $10-20 \%$
- $21-40 \%$
Dais de $40 \%$ 
11. A adoção dos padrões internacionais reduziu o número de testes e inspeções realizadas em seus produtos?

$\square$ Nenhuma redução

Alguma redução

Significativa redução

$\square$ Remoção dos testes requisitados

$\square$ Nenhuma das anteriores

- Isso reduziu os custos de exportação?

$\square \operatorname{Sim} \square$ Não

Em caso positivo:

- Indique a porcentagem de redução.

- $1-4 \%$

$\square-9 \%$

口 $10-20 \%$

- $21-40 \%$

- Mais de $40 \%$ 